\title{
O PROJETO NEOCONSERVADOR PARA A EDUCAÇÃO BRASILEIRA E SUAS DISTORÇÕES NAS CONCEPÇÕES DE JUSTIÇA SOCIAL, INCLUSÃO E DEMOCRACIA: CONSIDERAÇÕES ACERCA DO “AJUSTE JUSTO” PROPOSTO PELO BANCO MUNDIAL
}

\author{
The neoconservative project for brazilian education and its distortions in the \\ conceptions of social justice, inclusion and democracy: considerations about the \\ "fair adjustment" proposed by the World Bank
}

El proyecto neoconservador de educación brasileña y sus distorsiones en las concepciones de justicia social, inclusión y democracia: consideraciones sobre el "ajuste justo" propuesto por el Banco Mundial

\author{
José dos Santos Souza* \\ Jussara Marques de Macedo**
}

\begin{abstract}
Resumo
O artigo analisa os impactos políticos e ideológicos das proposições contidas no documento $U m$ Ajuste Justo: análise da eficiência e equidade do gasto público no Brasil, publicado em novembro de 2017 pelo Grupo Banco Mundial sob encomenda do Governo Brasileiro. O objetivo do artigo é explicitar a identidade do conteúdo deste documento com o projeto neoconservador para a educação brasileira em curso no país desde agosto de 2016, com a posse do presidente Michel Temer, aprofundado pelo governo Bolsonaro. Trata-se de excerto de pesquisa mais ampla acerca dos novos modelos de gestão de sistemas públicos de ensino e precariedade do trabalho docente. A análise qualitativa, de caráter explicativo, baseia-se em fontes documentais para coleta de dados. Os resultados apontam a falta de originalidade nas proposições do documento Um Ajuste Justo, pois tais proposições faziam parte da agenda do projeto neoconservador do Bloco no Poder no Brasil. Este projeto visa superar os efeitos da crise orgânica do capital por meio de medidas para reorientar o uso do fundo público em favor dos grandes empresários, em detrimento da classe trabalhadora. Com base na lógica mercantil, este projeto se materializa no campo educacional como medidas de controle da gestão dos sistemas públicos de ensino não só para racionar custos, mas para repassar para os usuários o custo serviços prestados pelos sistemas públicos de ensino.
\end{abstract}

PALAVRAS-CHAVE: Organismos Internacionais. Política Educacional. Ação Governamental. Neoliberalismo e Educação. Neoconservadorismo e Educação.

\footnotetext{
* Doutor em Sociologia pela Universidade Estadual de Campinas (UNICAMP). Professor associado IV de Economia Política da Educação e de Política Educacional do Departamento de Educação e Sociedade do Instituto Multidisciplinar da Universidade Federal Rural do Rio de Janeiro, docente do Programa de PósGraduação Stricto Sensu em Educação (PPGEduc/UFRRJ). Coordena o Curso de Pós-Graduação Lato Sensu em Gestão Educacional (CEGEd), atua no quadro docente de cursos de licenciatura. Endereço profissional: Est. da Água Grande, 303, Bloco II/1710 - Irajá - Rio de Janeiro - RJ - CEP: 21230-362. Email: jsantos@ufrrj.br Orcid:_https://orcid.org/0000-0001-5433-0812

** Doutora em Educação pela Universidade Federal Fluminense (UFF). Atua como professora adjunta do Departamento de Administração Educacional (EDA) e compõe o quadro docente do Programa de PósGraduação Strictu Senso Políticas Públicas em Direitos Humanos (PPDH) da Universidade Federal do Rio de Janeiro (UFRJ). E-mail: jussara0712@gmail.com Orcid: https://orcid.org/0000-0001-6641-3164
} 


\begin{abstract}
The article analyzes the political and ideological impacts of the proposals contained in the document A Fair Adjustment: analysis of the efficiency and equity of public spending in Brazil, published in November 2017 by the World Bank at the request of the Brazilian Government. The purpose of the article is to make explicit the identity of the content of this document with the neoconservative project for Brazilian education underway in the country since August 2016, with the coming to power of President Michel Temer, further developed by the Bolsonaro government. This is an excerpt from a broader research on the new management models of public education systems and the precariousness of teaching work. The qualitative analysis, of explanatory character, is based on documentary sources for data collection. The results point to the lack of originality in the propositions of the document A Fair Adjustment, as such propositions were already part of the agenda of the neoconservative project of the ruling class in Brazil. This project aims to overcome the effects of the capital's organic crisis through measures to reorient the use of the public fund in favor of large businessmen, to the detriment of the working class. Based on market logic, this project materializes in the educational field as measures to control the management of public education systems not only to ration costs, but to pass on to users the cost of services provided by public learning systems.
\end{abstract}

KEYWORDS: International Organisms. Educational Policy. Government Action. Neoliberalism and Education. Neoconservatism and Education.

\title{
Resumen
}

El artículo analiza los impactos políticos e ideológicos de las propuestas contenidas en el documento Um Ajuste Justo: análisis de la eficiencia y equidad del gasto público en Brasil, publicado en noviembre de 2017 por el Banco Mundial a solicitud del gobierno brasileño. El objetivo del artículo es hacer explícita la identidad del contenido de este documento con el proyecto neoconservador para la educación brasileña en curso en el país desde agosto de 2016, con la inauguración del presidente Michel Temer, desarrollado por el gobierno de Bolsonaro. Este es un extracto de una investigación más amplia sobre los nuevos modelos de gestión de los sistemas de educación pública y la precariedad del trabajo docente. El análisis cualitativo, de carácter explicativo, se basa en fuentes documentales para la recopilación de datos. Los resultados apuntan a la falta de originalidad en las propuestas del documento Um Ajuste Justo, ya que tales propuestas son parte de la agenda del proyecto neoconservador del Bloco no Poder para superar los efectos de la crisis orgánica del capital a través de medidas para reorientar el uso de fondos públicos en favor de los grandes capitalistas, en detrimento de la clase trabajadora. Basado en la lógica del mercado, este proyecto se materializa en el campo educativo como medidas para controlar la gestión de los sistemas de educación pública, no solo para racionar los costos, sino para transmitir a los usuarios el costo de los servicios prestados por los sistemas de educación pública

PALABRAS CLAVE: Organismos Internacionales. Política Educativa. Acción Gubernamental. Neoliberalismo y Educación. Neoconservadurismo y Educación.

\section{INTRODUÇÃO}

Nas duas últimas décadas temos vivenciado reformas brutais na Educação Superior brasileira. A gestão educacional tem sido pautada pelos princípios da "Nova Gestão Pública" (SOUZA, 2015; MACEDO, 2016), de modo que o governo federal tem acionado medidas bastante duras para racionalizar recursos destinados às universidades federais. Para isto, vale-se de estratégias de avaliação externa em larga escala, da aplicação de princípios de accountability e de medidas de engessamento da 
gestão financeira por meio do Tribunal de Contas da União (TCU) em nome de uma suposta produtividade racional. Além disto, busca ampliar o número de estudantes sem devido planejamento nem adequada ampliação da infraestrutura física e do quadro de docentes e de técnicos administrativos, visando aumentar a relação do número de alunos por professor sem considerar outra atividades da universidade além do ensino - a pesquisa e a extensão, por exemplo. Ataca a carreira docente e a livre organização sindical da categoria, além de promover o achatamento salarial, amparando-se na Ementa Constitucional (EC) $n^{\circ}$ 95/2016 (BRASIL, 2016) e a hierarquização de funções docentes, de modo que uns são encarregados de ministrar aulas e uma pequena fração responsável pelo desenvolvimento de pesquisas científicas.

Também faz parte desta iniciativa a diversificação de instituições de ensino superior por meio da ampliação considerável do número de faculdades, centros universitários, institutos superiores em detrimento da ampliação e fortalecimento de universidades. Esta ampliação tem assumido caráter eminentemente privado, onde o ensino à distância tem se tornado forte filão de mercado, haja vista a considerável proliferação desta modalidade de ensino desde a década de 2000 (Cf.: ARAÚJO, 2016; e SILVA Jr.; MARTINS, 2016). Esta ampliação da iniciativa privada na educação tem sido acompanhada de sistemática ofensiva o capital no setor público do ensino, onde as universidades públicas se tornaram alvo principal das ações governamentais de racionamento de recursos financeiros, materiais e humanos.

Todas essas ações do governo federal se alinham com o propósito do Bloco no Poder $^{1}$ de reorientar o uso do fundo público por meio da redefinição da relação entre Estado e Sociedade materializada na ampla reforma do Estado em curso no país. Tal reorientação, por sua vez, nada mais é do que a expressão superestrutural da contrarreforma burguesa para recompor suas bases de acumulação corroídas pela crise orgânica do capital instalada desde os aos 1970. A contrarreforma burguesa tem sua materialidade determinante nas mudanças recentes no regime de acumulação capitalista pautado na produção enxuta e flexível, de modo que, articulada às reorientações no campo superestrutural, configuram verdadeira recomposição burguesa diante da crise orgânica do capital (SOUZA, 2015; 2016; 2019).

Neste artigo, tomaremos como referência empírica uma ação do Governo Brasileiro articulada com o Grupo Banco Mundial, logo no início do mandato do presidente Michel Temer, assim que tomou posse, após o impeachment da presidenta Dilma Rousseff. Nosso objetivo é explicitar o caráter excludente do projeto neoconservador para a educação brasileira. A partir de análise de documentos, buscaremos evidenciar as distorções promovidas por este projeto político nas concepções de justiça social, de inclusão e de democracia. Posteriormente, tratamos da relação entre este projeto político e o processo de recomposição burguesa diante da crise orgânica do capital a fim de resgatar a regularidade da acumulação de capital sob um modo de regulação social neoconservador.

\footnotetext{
${ }^{1}$ Bloco no Poder é um conceito de Poulantzas (1977) para expressar a relação existente entre diferentes frações da classe dominante e o Estado. Trata-se de uma unidade contraditória entre as diferentes frações da classe dominante em nome de seus interesses coletivos diante da luta entre as classes sociais. Esta unidade é protagonizada pelo Estado, que atua como instituição educadora da sociedade civil para o consenso, de modo a mediar o conflito de classes em nome dos interesses coletivos burgueses. Portanto, trata-se de uma unidade política, econômica e ideológica entre diferentes frações da burguesia como meio para manter sua dominação sobre a classe trabalhadora (BERRINGER, 2015, p. 10).
} 


\section{O ajuste (in)justo do Grupo Banco Mundial encomendado pelo governo brasileiro}

A pedido do Governo Brasileiro, o Grupo Banco Mundial fez publicar o relatório intitulado "Um ajuste justo: análise da eficiência e equidade do gasto público no Brasil". . Sem qualquer traço de justiça social, tampouco de eficiência e equidade, este documento ratifica a pedagogia política do capital para a mediar do conflito de classes, utilizando-se de um discurso pseudocientífico, de caráter tecnocrático, na construção do consenso em torno da necessidade de medidas austeras para economizar pelo menos $7 \%$ do PIB em potenciais economias fiscais em nível federal até 2026 (BANCO MUNDIAL, 2017, p. 14).

Esse corte de 7\% do PIB nos investimentos sociais seriam extraídos dos setores: $1,8 \%$ do PIB resultante da proposta de reforma previdenciária (negociada no Congresso em maio de 2017); 0,9\% do PIB em reduções na massa salarial dos servidores públicos; 0,2\% do PIB em ganhos de eficiência em aquisições públicas; $1,3 \%$ do PIB resultantes da racionalização dos programas de assistência social e de apoio ao mercado do trabalho; $2 \%$ do PIB em reduções nos créditos subsidiados e nos gastos tributários de apoio às empresas; $0,3 \%$ do PIB por meio da eliminação de créditos tributários para a saúde; $0,5 \%$ do PIB em reformas no financiamento do ensino superior; $1,3 \%$ do PIB resultante de reformas para melhorar a eficiência nos setores de saúde e educação (BANCO MUNDIAL, 2017, p. 14).

A estrutura argumentativa desse documento do Grupo Banco Mundial é a ideologia da sustentabilidade fiscal, ou seja, a apologia de um modelo de gestão físcal supostamente capaz de manter o equilíbrio das contas públicas por um determinado período como meio de viabilizar o atendimento das demandas por bens e serviços públicos, sem esclarecer exatamente de quem seriam tais demandas. Ao não explicitar de que demandas exatamente se tem em foco, a ideologia da sustentabilidade fiscal ofusca o ímpeto dos propagadores desta ideologia em construir o consentimento ativo da sociedade civil para as medidas de reorientação do uso do fundo público em favor do grande capital e em detrimento da grande maioria da população, que é a classe trabalhadora. Este discurso parte do pressuposto de que o Governo Brasileiro gasta mais do que pode e, além disso, gasta mal. ${ }^{3}$ Afirma que, ao longo das duas últimas décadas, o Brasil observou um consistente aumento dos gastos públicos, o que agora coloca em risco a sustentabilidade fiscal. Com base nesta compreensão, os "especialistas" do Banco avaliam que o limite constitucional de gastos ("teto de gastos") adotado pela EC $n^{\circ} 95 / 2016$, que limita por 20 anos os gastos públicos, introduziu uma trajetória de ajuste gradual para os gastos públicos ao longo dos próximos dez anos (BRASIL, 2016). A partir dessa estrutura argumentativa, esses "especialistas" explicitam uma clara pretensão no documento: demonstrar como a ação governamental materializada na EC $n^{\circ} 95 / 2016$ pode ser implementada de forma a proteger os mais pobres e vulneráveis e minimizar os impactos negativos sobre os empregos e a prestação de serviços públicos.

Nesse sentido, os "especialistas" do Grupo Banco Mundial traçam medidas que apontam para a redução dos gastos, mas alertam que não é a única estratégia para

\footnotetext{
2 Segundo é mencionado no próprio documento, a iniciativa partiu do Governo Brasileiro: "Atento à mudança de cenário, o governo federal solicitou ao Banco Mundial a elaboração deste relatório, com o objetivo de realizar uma análise aprofundada dos gastos do governo, identificar alternativas para reduzir o déficit fiscal a um nível sustentável e, ao mesmo tempo, consolidar os ganhos sociais alcançados nas décadas anteriores" (BANCO MUNDIAL, 2017, p. 01).

3 Pressuposto este que não é original, afinal ele tem sido amplamente difundido no Brasil pelos intelectuais orgânicos deste organismo internacional desde os anos 1990, como por exemplo, Castro (1995).
} 
restaurar o equilíbrio fiscal, mas é uma condição necessária. Sugerem que, em vez de cortar seus gastos, o governo brasileiro deveria aumentar suas receitas tributárias e reduzir os altos pagamentos de juros sobre sua dívida pública. Mas não relutam em chegar ao cerne da questão, quando apontam que a fonte mais importante de economia fiscal de longo prazo é a reforma previdenciária. O documento aponta que serão necessárias medidas adicionais para tornar o sistema previdenciário mais equitativo e sustentável financeiramente. Nesta linha argumentativa, afirmam que a reforma é socialmente justa, pois reduziria principalmente os subsídios concedidos a trabalhadores que recebem acima de três salários mínimos.

\section{Para ajustar a gestão pública}

No que concerne à gestão pública, o documento aponta para a "melhora" dos métodos de aquisições públicas de bens e serviços, o que segundo os "especialistas", geraria economias em todos os níveis de governo. Assim, o ajuste injusto do Banco Mundial propõe uma redução dos gastos entre 24 e 35 bilhões em três anos, somente por intermédio de melhor planejamento e estratégias de licitações, seguindo políticas já existentes (BANCO MUNDIAL, 2017, p. 10).

Além dessa medida, o documento avança para a argumentação de que as despesas com políticas de apoio às empresas cresceram rapidamente, atingindo 4,5\% do PIB em 2015, sem evidências de que os programas existentes tenham sido eficazes e eficientes em seu objetivo de impulsionar a produtividade e a geração sustentável de empregos. A partir desta indicação, o BM propõe a redução de custos do PSI (associados a empréstimos existentes a juros subsidiados) de aproximadamente 0,4\% do PIB em 2018, para 0,1\% do PIB até 2026 (BANCO MUNDIAL, 2017, p. 10-11).

Os programas de proteção social e emprego também se beneficiariam de reformas que introduzissem incentivos mais bem alinhados e mantivessem o foco nos grupos populacionais mais vulneráveis. Portanto, o BM propõe melhor coordenação das políticas e uma maior integração das funções de gestão e prestação de serviços, de modo a reduzir sobreposições, economizar recursos e realinhar os incentivos para aumentar a produtividade da força de trabalho. Para isto, apontam a necessidade de reformular e integrar os programas de proteção social (programas de apoio ao mercado do trabalho, assistência social e aposentadorias sociais) em um sistema coerente que faça melhor uso da capacidade brasileira de identificar famílias carentes e, assim, obter economias fiscais, o que geraria, segundo o Banco, uma economia de até 1,3\% do PIB ao longo da próxima década (BANCO MUNDIAL, 2017, p. 11).

\section{Para ajustar a gestão da educação brasileira}

No que concerne à Educação Básica, o ajuste injusto do Banco Mundial propõe a redução de $37 \%$ de recursos no Ensino Fundamental e $47 \%$ no Ensino Médio para a manutenção do desempenho atual dos serviços de educação, o que corresponderia, segundo o BM, a uma economia de aproximadamente $1 \%$ do PIB (BANCO MUNDIAL, 2017, p. 13). Além disto, propõe aumentar o número de alunos por professor em $33 \%$ no Ensino Fundamental e $41 \%$ no Ensino Médio, o que, segundo o $\mathrm{BM}$, economizaria $\mathrm{R} \$ 22$ bilhões (0,3\% do PIB) por ano. Cinicamente sugerem que isto poderia ser realizado simplesmente pela promoção do declínio natural do número de professores, sem substituir todos os profissionais que se aposentarem ou venham à óbito 
no futuro, até se atingir a razão eficiente aluno/professor (BANCO MUNDIAL, 2017, p. 13).

O nível de crueldade não para por aí. O documento aponta para a necessidade de revisão da vinculação constitucional dos gastos em educação a $25 \%$ das receitas dos municípios, o que para o Banco Mundial seria uma das principais causas da ineficiência dos gastos, uma vez que existe a probabilidade de municípios mais ricos, com uma alta taxa de receita corrente liquida por aluno, serem bem menos eficientes que municípios mais pobres. Curiosamente, não há no documento nenhum estudo qualificado que aponte tal probabilidade (BANCO MUNDIAL, 2017, p. 13).

Ao comparar as universidades federais com universidades privadas sem qualquer critério, o Documento desconsidera o resultado das avaliações em larga escala feitas pelo Instituto Nacional de Estudos e Pesquisas Educacionais Anísio Teixeira (INEP), que apontam as universidades públicas como as mais eficientes do país. A despeito de tal avaliação, os "especialistas" do Banco Mundial apontam que os níveis de gastos por aluno nas universidades públicas são de duas a cinco vezes maior que o gasto por aluno em universidade privadas, sem considerar que as públicas articulam ensino, pesquisa e extensão, o que não ocorre na maioria absoluta das privadas. Apontam que o Governo Federal gasta aproximadamente $0,7 \%$ do PIB com universidades federais e que aproximadamente um quarto desse dinheiro é desperdiçada (BANCO MUNDIAL, 2017, p. 13-14).

A partir destas considerações, o documento argumenta que, embora os estudantes de universidades federais não paguem por sua educação, mais de $65 \%$ deles pertencem aos $40 \%$ mais ricos da população e que, portanto, as despesas com universidades federais equivalem a um subsídio regressivo à parcela mais rica da população brasileira (BANCO MUNDIAL, 2017, p. 13).

Esses argumentos levam à proposição de uma reforma do Sistema Federal de Ensino Superior para reduzir os custos de $0,7 \%$ do PIB para $0,2 \%$, de modo a garantir uma economia de $0,5 \%$ do PIB do orçamento federal. Esta reforma consistiria na limitação do financiamento a cada universidade, de modo que se dê com base no número de estudantes, a exemplo do que já ocorre na Educação Básica, acusando que isto geraria uma economia de aproximadamente 0,3\% do PIB (BANCO MUNDIAL, 2017, p. 13).

Sugerem ainda que, uma vez que diplomas universitários geram altos retornos pessoais (em termos de salários mais altos), o Brasil siga o exemplo da maioria dos outros países que cobram pelo ensino fornecido em universidades públicas e ofereça empréstimos públicos que podem ser pagos com os salários futuros dos estudantes, como o FIES, por exemplo (BANCO MUNDIAL, 2017, p. 14).

Além desse ataque frontal à gratuidade da Educação Superior nas universidades federais, outro ataque também é articulado de forma indireta, por meio de proposições de ajustes na previdência social. Consta no documento a proposição de reduzir ainda mais as taxas de reposição em 20 pontos percentuais, o que reduziria o que chamam de déficit da previdência em $1,8 \%$ do PIB no médio prazo. Propõem também desvincular o valor mínimo de aposentadoria do salário mínimo (e corrigi-la somente pelos aumentos do custo de vida), o que afirmam ter maior impacto na redução do chamam de déficit fiscal. É curioso que esta medida tão dramática evitaria uma redução adicional no suposto déficit da previdência de no máximo $0,5 \%$ do PIB em 2026, podendo chegar a uma redução de apenas 2,3\% em 2067 (BANCO MUNDIAL, 2017, p. 72). O ataque se estende aos aposentados rurais, quando sugerem o reconhecimento de que as 
aposentadorias rurais são, de fato, programas sociais. Portanto, a reforma deveria considerá-los como tal, uma vez que ambos esses sistemas previdenciários são, de facto, não contributivos, e seu objetivo é evitar que idosos caiam na pobreza. No entanto, diferentemente do programa Bolsa Família, que é bem direcionado aos mais pobres, na visão dos "especialistas" do Banco, as aposentadorias e pensões sociais não são bem focadas aos indivíduos pobres. Eles acusam que, na verdade, $70 \%$ dos beneficiários do BPC e 76\% dos beneficiários das aposentadorias rurais não pertencem ao grupo dos $40 \%$ mais pobres da população (BANCO MUNDIAL, 2017, p. 09). Ademais, consideram que o nível dos benefícios concedidos por esses programas é muito mais alto que o de outros programas de assistência social - o benefício máximo concedido pelo Bolsa Família é cerca de um terço do que é concedido pelo BPC e pelas aposentadorias rurais. Assim, propõem uma reforma para consolidar as aposentadorias sociais com outros programas de assistência social poderia gerar economias significativas por meio de um melhor direcionamento e, potencialmente, liberar recursos para necessidades sociais urgentes, tais como o acesso a saneamento básico, educação infantil e assistência aos idosos (BANCO MUNDIAL, 2017, p. 09).

Somado ao argumento de que o déficit da previdência e a iniquidade do sistema previdenciário como um todo poderiam ser solucionados por meio da remoção dos privilégios concedidos aos servidores públicos contratados antes de 2003, surgem também o argumento de que os servidores públicos recebem um "Prêmio Salarial". Isto seria a diferença a mais no salário dos servidores públicos em relação ao salário pago pela iniciativa privada para o mesmo serviço, considerando as mesmas características dos trabalhadores (idade e experiência) e o nível educacional (BANCO MUNDIAL, 2017, p. 10 e 46-47). Não há estudos aprofundados que possam assegurar a evidência desse suposto "prêmio salarial" dos servidores públicos, conforme é reconhecido pelo próprio documento. $\mathrm{O}$ argumento de "prêmio salarial" somado ao de "privilégios do serviço público" alimentam a ideologia privatista que funciona como base de construção do consenso em torno dos ataques ao serviço público, ao passo que mascaram as verdadeiras intenções do discurso que é a privatização das políticas sociais para garantir a reorientação do uso do fundo público em favor do grande capital. Não obstante, os "especialistas" do Banco partem do pressuposto de que o nível dos salários dos servidores públicos federais é, em média, 67\% superior aos do setor privado, mesmo após levar em consideração o nível de educação e outras características dos trabalhadores como idade e experiência. Cinicamente, usam a expressão "prêmio salarial do setor público" para apontar que essa suposta elevação salarial dos servidores em relação ao setor privado é atípica em relação a padrões internacionais. Com essa argumentação, o documento propõe que a massa salarial do funcionalismo público seja reduzida significativamente. Inclusive apontam que a redução dos "prêmios salariais" excepcionalmente altos dos servidores públicos também seria desejável de um ponto de vista de equidade, uma vez que a grande maioria (83\%) dos servidores públicos federais integram o quintil mais rico da população. O Banco propõe a redução pela metade do "prêmio salarial" em relação ao setor privado (BANCO MUNDIAL, 2017, p. 10 e 4647).

Embora reconheçam que ainda são necessários estudos aprofundados para comparar as remunerações dos setores público e privado, apontam que os dados disponíveis já são suficientes para recomendar a suspensão de reajustes nas remunerações do funcionalismo no curto prazo, enquanto se desenvolvem estudos mais detalhados sobre o valor adequado de remuneração das diversas carreiras públicas. 
A "Nova Gestão Pública" é apontada no Documento como o ambiente profícuo para os ajustes, pois, além do ajuste fiscal proposto, o Banco aponta também a necessidade de melhoria da qualidade das despesas públicas, o que exigiria a institucionalização de um sistema regular e rigoroso de monitoramento e avaliação das políticas públicas (BANCO MUNDIAL, 2017, p. 15). Consta no documento que o monitoramento deve manter seu foco nos resultados e vincular tais resultados aos insumos orçamentários. De acordo com a perspectiva da accountability o Documento argumenta que a avaliação pode fornecer dados para subsidiar a escolha das soluções mais eficazes para que as políticas públicas atinjam seus objetivos e, assim, orientar as decisões sobre quais programas devem ser suspensos, mantidos ou expandidos (BANCO MUNDIAL, 2017, p. 15). Além do arcabouço institucional, o monitoramento e avaliação regulares da eficiência dos gastos exigirão uma maior disponibilidade de dados administrativos. Atualmente, as restrições de acesso a informações, especialmente em relação aos gastos tributários (do Ministério da Fazenda) e à incidência de programas sociais (do IBGE e do Ministério do Desenvolvimento Social), limitam a disponibilidade dos dados rigorosos necessários para tomar decisões bem embasadas. Permitir que pesquisadores de fora do governo tenham acesso a tais dados - como é prática comum na maioria dos países da OCDE - poderia aumentar a credibilidade e a busca de eficiência (BANCO MUNDIAL, 2017, p. 15).

Enfim, o velho argumento do único caminho possível. Os "especialistas" afirmam categoricamente que, caso não consiga fazer isso, o Brasil inevitavelmente passará por outras crises fiscais e terá de implementar outros ajustes dolorosos no futuro.

\title{
O Projeto Político Neoconservador e a Distorção de Justiça Social, Inclusão e Democracia
}

Considerando que a base fundamental do documento Um Ajuste Justo seja "justiça social", torna-se oportuno retomar a discussão de o que vem a ser isto. Pois bem,

\begin{abstract}
Quando se pode dizer que uma pessoa ou instituição é justa ou injusta? Em outras palavras, quando se sabe ou se pode afirmar que as ocorrências cotidianas refletem arranjos sociais justos? A temática tem sido objeto de reflexão desde a Antiguidade. Em sua vertente mais difundida, a ideia de justiça tem sido tratada em termos de uma justiça distributiva e encontrado seu princípio fundamental na máxima "Dê a cada indivíduo o que lhe é devido", seja com base em suas necessidades, em seu mérito ou em suas escolhas. Ao longo do tempo, a figura da balança tem servido de representação simbólica da imparcialidade ante as reivindicações por justiça. Trata-se de perspectivas históricas, que variam conforme os valores e os bens dominantes em cada sociedade, portanto sujeitas às ideologias, uma vez que se assentam em concepções de mundo que emergem de relações sociais concretas (PIZZIO, 2016, p. 356).
\end{abstract}

A concepção de justiça social, portanto, é um campo em disputa. “[...] A discussão sobre o que é justo ou injusto, particularmente em relação à partilha de recompensas e ônus sociais, encontra-se permeada pelo debate sobre a igualdade e a desigualdade na distribuição de bens sociais" (PIZZIO, 2016, p. 357). Considerando o conflito de classes, percebe-se a existência de dois campos distintos e conflitantes de compreensão acerca da justiça social - um da perspectiva da classe trabalhadora e outro da perspectiva do capital. De acordo com a perspectiva da classe trabalhadora, esta concepção vem sendo construída no decurso da luta contra a exploração do trabalho. Já 
na perspectiva burguesa, esta concepção sempre esteve amparada pela ideia de sustentabilidade da acumulação capitalista.

O que o documento Um Ajuste Justo propõe como meios de garantir a justiça social é: romper com a ideia de direitos adquiridos; reorientar os cálculos dos gastos públicos para garantir a sustentabilidade fiscal; promover reforma da previdência para socializar ônus; tratar o magistério do ensino superior das universidades públicas ensino, pesquisa e extensão em dedicação exclusiva - com critérios similares aos que são aplicados pelas instituições de ensino privadas para remunerar o trabalho de seus professores - atividade restrita ao ensino, por hora/aula, com remuneração ínfima (BANCO MUNDIAL, 2017, pp. 11, 34, 82, 89). O que é entendido no documento como justiça consiste no ataque às conquistas históricas do movimento organizado dos trabalhadores, apontadas como injustiça social. A justiça social para o Grupo Banco Mundial consiste exatamente na deturpação do caráter justo das conquistas dos trabalhadores.

O documento Um Ajuste Justo não faz qualquer referência à inclusão social. Embora existam diferentes abordagens acerca de inclusão social, há certa confluência em diferentes pensadores para o entendimento de que cabe ao Estado o papel de garantir as condições para que ela se efetive:

\begin{abstract}
No âmbito da inclusão social destaca-se a abordagem da solidariedade social com o envolvimento de todos os segmentos da sociedade. Entretanto, todas as ações de inclusão social requerem uma gestão económica, mais concretamente, uma política social. Nesse contexto, alguns autores [...] responsabilizam o Estado pela implementação de programas de inclusão social (ALVINO-BORBA; MATA-LIMA, 2011).
\end{abstract}

Entretanto, o que se percebe nas proposições do Grupo Banco Mundial nada mais é do que uma retórica tecnocrática para desresponsabilizar o Estado desta tarefa ou pelo menos diminuir sua responsabilidade. Pior ainda é que esta retórica vem acompanhada de uma justificativa de que este seria o caminho para garantir a justiça social. Embora pareça absurda, a retórica do documento Um Ajuste Justo se estrutura sob o argumento de que se deve eximir o Estado da responsabilidade de incluir ou ao menos reduzir drasticamente seus gastos com políticas de inclusão como forma de inclusão social. Uma retórica no mínimo cínica!

Não surpreende o fato de que nas 160 páginas do documento Um Ajuste Justo a palavra "democracia" ou "democrático(a)" não apareçam uma única vez. Afinal, as concepções de justiça social e de inclusão social em que o documento se pauta demonstram que não há qualquer espaço para valores democráticos em suas proposições. Portanto, é natural que estas palavras sejam ausentes em seu discurso. Todavia, esta ausência é camuflada por uma retórica fatalista de um projeto político neoconservador colocado como único caminho possível para evitar o caos. Assim, o caráter ideológico do Documento Um Ajuste Justo ganha maior clareza, uma vez que veio para atender à demanda de um Governo Golpista que pretendia justificar suas medidas mais nefastas que viriam a ser estendidas pelo governo que o sucedeu, a versão indubitavelmente mais grotesca desta estirpe de governos materializada na figura de Jair Bolsonaro, dando materialidade a uma tendência mundial (Cf.: BBC, 2019).

\title{
CONCLUSÃO
}


O cenário em que se trava a disputa entre duas concepções distintas e conflitantes de justiça social, inclusão e democracia é aquele em que, a despeito do notável avanço científico e tecnológico, a classe trabalhadora é subsumida pela lógica mercantil, conformada pela promessa integradora do capital, ao mesmo tempo em que é alijada do acesso aos benefícios que a ciência e a tecnologia podem proporcionar. Nesta perspectiva, a justiça social não se efetiva nem no aspecto formal nem material. ${ }^{4}$ Por outro lado, a burguesia amplia cada vez mais suas margens de apropriação do trabalho excedente, utilizando-se da ciência e da tecnologia para ampliar as taxas de mais-valia relativa. Quando este movimento se vê ameaçado pelas consequências da concorrência intercapitalista, quando se configura a crise orgânica do capital ${ }^{5}$ a partir dos anos 1970 , percebe-se a articulação de uma verdadeira ofensiva do capital para garantir a institucionalidade necessária para suas medidas de reestruturação do trabalho e da produção em busca de nova regularidade para a acumulação de capital sob condições renovadas: por meio do trabalho e da produção enxuta e flexível.

Para garantir as condições objetivas e subjetivas necessárias à efetividade desta reestruturação produtiva, promove-se ampla reforma do Estado, redefine-se sua relação com a sociedade cujo único intuito é reorientar o uso do fundo público em favor do grande capital e em detrimento da garantia de justiça social e de inclusão numa perspectiva democrática. Para isto, são acionados conceitos e métodos da administração empresarial para submeter o serviço público a novos valores e padrões organizativos a pretexto de se implantar uma Nova Gestão Pública menos burocrática, mais eficiente e com foco em resultados (SOUZA, 2017). A ideia de um serviço público que tem no cidadão o seu cliente é apresentada como novo padrão de relação democrática entre Estado e sociedade, pretensamente a única forma de se garantir a justiça social e a inclusão possível, obviamente condicionadas pelos princípios da sustentabilidade fiscal.

Apesar deste projeto político ter se tornado hegemônico no Brasil e a reforma gerencial do Estado ter fincado raízes em diferentes esferas da administração pública, inclusive na gestão educacional,

[...] tudo leva a crer que, apesar de ter avançado a accountability, não há evidências de que isso tenha garantido maior qualidade do serviço público. Tampouco se percebe grandes alterações no que tange à baixa capacidade de controle social sobre a administração pública. Por outro lado, a implementação do gerencialismo tem sido eficaz na redefinição da relação entre Estado e sociedade, na capacidade de mediação do conflito de classes e no redirecionamento do uso do fundo público (SOUZA, 2017, p. 185).

Neste aspecto, o Grupo Banco Mundial, assim como outros organismos internacionais como a OIT, UNESCO, OCDE e OMC têm funcionado como uma espécie de intelectuais orgânicos coletivos do capital mobilizados para promover determinada pedagogia política renovada e, assim, instrumentalizar os governos, especialmente aqueles de países dependentes, na mediação do conflito de classes. Em

\footnotetext{
${ }^{4}$ De acordo com Pizzio, “[...] a ideia de justiça formal encontra-se amplamente alicerçada no pressuposto de que as distribuições devam ser realizadas com base em critérios ou regras existentes ou aceitas. Geralmente aparece identificada com a justiça jurídica e/ou individual e implica igualdade formal, caso se entenda que, em uma sociedade, todas as pessoas devam ser tratadas segundo as mesmas regras. [...] A justiça material, por sua vez, relaciona-se com a identificação de critérios distributivos adequados em relação à riqueza socialmente produzida e aos seus benefícios" (CAMPBELL, 1996 apud Pizzio, 2016, p. 357).

${ }^{5}$ Conforme já apontado em Souza (2015), diversos estudiosos apontam o esgotamento do modelo de desenvolvimento taylorista-fordista que configura a crise estrutural do capital. Dentre eles, podemos citar: Mészáros (2002), Hobsbawn (2008), Harvey (1992), Chesnais (1996), Anderson (1995), Antunes (2000, 2004, 2006) e Alves (2000).
} 
lugar de agentes externos que impõem diretrizes aos países, na realidade, estes organismos são parceiros dos governos na tarefa de conservar as condições objetivas e subjetivas da acumulação do capital.

Pronko (2019) observa que desde a década de 2000, o Banco Mundial tem redefinido sua atuação no campo educacional, especialmente no que se refere a países da periferia do capitalismo. De um lado, busca redefinir o papel dos sistemas educacionais no conjunto das estratégias de governo na perspectiva do desenvolvimento sustentável e do "combate à pobreza". De outro lado, busca induzir os países periféricos a incorporarem em suas agendas de governo certo behaviorismo, com foco na modelagem das condutas da população para a promoção de processos de tomada de decisões, de modo a promover junto à população pobre sua inserção produtiva ou, pelo menos, sua conformação ética e moral a contextos cada vez mais adversos de trabalho e de vida precária. Nesta perspectiva analítica, ao antecipar medidas de ajuste fiscal que o governo brasileiro tinha em sua agenda, o documento Um Ajuste Justo cumpre papel pedagógico importante no cenário político do país, pois visa educar a sociedade civil para a naturalização das medidas duras de desmonte das políticas públicas do Estado brasileiro imprescindíveis na garantia, ainda que precária, do mínimo de justiça social, de inclusão e de garantias de um Estado democrático de direito em que trabalhadores assumem status de cidadãos.

No campo educacional, o documento Um Ajuste Justo materializa a ofensiva do capital na gestão dos sistemas públicas de ensino a fim de racionalizar ao máximo os investimentos públicos em Educação Básica e em Educação Superior (tratados como gasto público). Esta ofensiva se dá prioritariamente pelo corte drástico de recursos financeiros e pelo enxugamento do quantitativo de profissionais da educação para equacionar as metas de redução do índice de relação professor/aluno e pela indução de mecanismos de para que os usuários dos serviços educacionais do Estado assumam gradativamente seu financiamento por meio de pagamento pelos serviços, inclusive por meio de financiamentos. Ao fim e ao cabo, o que o documento Um Ajuste Justo propõe, a pedido do Governo Brasileiro, nada mais é do que um ajuste injusto que compromete a justiça social, a inclusão e o acesso democrático ao conhecimento.

\section{REFERÊNCIAS}

ALVES, Giovanni. O novo (e precário) mundo do trabalho: reestruturação produtiva e crise do sindicalismo. São Paulo: Boitempo, 2000.

ALVINO-BORBA, Andreilcy; MATA-LIMA, Herlander. Exclusão e inclusão social nas sociedades modernas: um olhar sobre a situação em Portugal e na União Europeia. Serv. Soc. Soc., São Paulo, n. 106, p. 219-240, abr./jun. 2011.

ANDERSON, Perry. Balanço do neoliberalismo. In: SADER, E.; GENTILI, P. (Org.). Pós-neoliberalismo: as políticas sociais e o Estado democrático. Rio de Janeiro: Paz e Terra, 1995. p. 9-23.

ANTUNES, Ricardo. A desertificação neoliberal no Brasil (Collor, FHC e Lula). Campinas: Autores Associados, 2004. 
ANTUNES, Ricardo. Os sentidos do trabalho: ensaio sobre a afirmação e a negação do trabalho. 3. ed. São Paulo: Boitempo, 2000.

ANTUNES, Ricardo. Riqueza e miséria do trabalho no Brasil. São Paulo: Boitempo, 2006.

ARAÚJO, Rhoberta Santana de. Expansão do ensino superior e desenvolvimentismo: limites e contradições sob a hegemonia do Capital. Educação e Fronteiras On-Line, Dourados/MS, v. 6, n. 16 p. 93-105, jan./abr. 2016.

BANCO MUNDIAL. Um Ajuste Justo: análise da eficiência e equidade do gasto público no Brasil. 2017. Disponível em: <http://documents.worldbank.org/curated/en/884871511196609355/pdf/121480-

REVISED-PORTUGUESE-Brazil-Public-Expenditure-Review-Overview-PortugueseFinal-revised.pdf $>$. Acesso em 09/05/2020.

BBC. Quem são os líderes por trás do avanço da direita radical na Europa: Forças populistas de extrema direita estão em ascensão na Europa, como mostram os resultados das eleições gerais da Espanha. G1 - Globo Notícias, 03/05/2019. Disponível em: $<$ https://g1.globo.com/mundo/noticia/2019/05/03/quem-sao-os-lideres-por-tras-doavanco-da-direita-radical-na-europa.ghtml>. Acesso em 14/05/2020.

BERRINGER, Tatiana. Bloco no poder e as análises de política externa. Revista de Estudos Internacionais (REI), vol. 6, n. 1, p. 5-21, 2015.

BRASIL. Emenda Constitucional $n^{\circ}$ 95, de 15 de dezembro de 2016. Altera o Ato das Disposições Constitucionais Transitórias, para instituir o Novo Regime Fiscal, e dá outras providências. Brasília (DF): 2016. Disponível em: $<$ http://www.planalto.gov.br/ccivil_03/constituicao/emendas/emc/emc95.htm $\geq$. Acesso em 09/05/2020.

CHESNAIS, François. A mundialização do capital. Trad. de Silvana Finzi Foa. São Paulo: Xamã, 1996.

HARVEY, David. Condição pós-moderna. Trad. de Adail Ubirajara Sobral. 14. ed. São Paulo: Loyola, 1992.

HOBSBAWN, Eric J. Era dos extremos: o breve século XX. Trad. de Marcos Santarrita. 10. ed. Rio de Janeiro: Cia. das Letras, 2008. 
MACEDO, Jussara M. Direito à educação no Brasil. RTPS - Revista Trabalho, Política e Sociedade, v. 1, n. 1, p. p. 41-60, 30 dez. 2016. DOI: http://dx.doi.org/10.29404/rtpsv1i1.3226

MACEDO, Jussara M.; MELLO, Míriam M. Fundamentos teóricos e metodológicos da precarização do trabalho docente. RTPS - Revista Trabalho, Política e Sociedade, v. 2, n. 3, p. p. 219-242, 30 dez. 2017. DOI: https://doi.org/10.29404/rtps-v2i3.3680

MÉSZÁROS, Istvan. Para além do capital: rumo a uma teoria da transição. Trad. de Paulo César Castanheira e Sérgio Lessa. São Paulo: Boitempo: Campinas: Edunicamp, 2002.

PIZZIO, Alex. Embates acerca da ideia de justiça social em relação a conflitos sociais e desigualdades. Rev. Adm. Pública, Rio de Janeiro, v. 50, n. 3, p. 355-375, jun./2016. DOI: https://doi.org/10.1590/0034-7612127748.

POULANTZAS, Nicos. Poder político e classes sociais. São Paulo: Editora Martins Fontes, 1977.

PRONKO, Marcela. Modelar o comportamento: novas estratégias do Banco Mundial para a educação na periferia do capitalismo. RTPS - Rev. Trabalho, Política $e$ Sociedade, Vol. IV, $\mathrm{n}^{\mathrm{o}}$ 06, p. 167-180, jan.-jun./2019. DOI: https://doi.org/10.29404/rtps-v4i6.248

SILVA Jr., João dos Reis, MARTINS, Tania Barbosa. Mediações e contradições na educação a distância: o trabalho do professor e do tutor. Educação e Fronteiras OnLine, Dourados/MS, v. 6 n. 16, p. 37-47, jan./abr. 2016.

SOUZA, José dos Santos. A Formação do Trabalhador no Contexto da Reconfiguração do Trabalho, da Produção e dos Mecanismos de Mediação do Conflito de Classe. Revista Contemporânea de Educação, v. 10, p. 50-66, 2015.

SOUZA, José dos Santos. Crise orgânica do capital, recomposição burguesa e intensificação da precariedade do trabalho docente: fundamentos sócio-históricos da (dês) configuração do trabalho docente. In: SILVA Jr., João dos Reis et al. Das crises do capital às crises da educação superior no Brasil - novos e renovados desafios em perspectiva. Uberlândia: Navegando, 2019. p. 19-36. DOI: http://doi.org/10.29388/97885-53111-53-4-0-f.19-36

SOUZA, José dos Santos. Cursos superiores de tecnologia: a materialidade da formação enxuta e flexível para o precariado no Brasil. Trabalho Necessário, Vol. 18, no 36, p. 01-22, mai.-ago./2020. DOI: https://doi.org/10.22409/tn.v18i36.38855 
SOUZA, José dos Santos. Gerencialismo. In: SEGENREICH, Stella Cecilia Duarte (Organizadora). Organização institucional e acadêmica na expansão da educação superior: glossário. Rio de Janeiro: Publit, 2017. p. 54-58.

SOUZA, José dos Santos. O recrudescimento da teoria do capital humano. Cadernos Cemarx, n. 3, 24 jul. 2006. Disponível em: <https://econtents.bc.unicamp.br/inpec/index.php/cemarx/article/view/10875>. Acesso em 13/05/2020.

SOUZA, José dos Santos. Reforma Gerencial e Novos Desafios para a Gestão do Trabalho Escolar. RTPS - Revista Trabalho, Política e Sociedade, v. 1, p. 09-20, 2016. DOI: http://doi.org/10.29404/rtps-v1i1.3298

SOUZA, José dos Santos. Trabalho, qualificação, ciência e tecnologia no mundo contemporâneo: fundamentos teóricos para uma análise da política de educação profissional. Revista da FAEEBA - Educação e Contemporaneidade, Salvador, v. 13, n. 22, p. 1-15, jul./dez., 2004.

Recebido:14-05-2020

Aprovado: 17/07/2020 